\title{
Development of Theoretical and Methodological Foundations of the Research of Enterprise Adaptive Potential in Terms of Ensuring Its Financial and Corporate Sustainability
}

\author{
Yu. Dolgikh ${ }^{1, *}$, E. Smorodina ${ }^{1}$, S. Arzumanian ${ }^{2}$ \\ ${ }^{1}$ Ural State University of Economics, Ekaterinburg, Russia \\ ${ }^{2}$ Tashkent Institute of Finance, Tashkent, Uzbekistan \\ *Corresponding author. Email: rimdm@rambler.ru
}

\begin{abstract}
The article is devoted to the of theoretical and methodological foundations development of the research of the adaptive potential of an enterprise in terms of the application of the conceptual provisions of the system methodology and the system stability theory. The authors substantiated that the adaptation of an enterprise to modifying external and internal factors indicates the most important feature of its sustainability, a quantitative measure of the enterprise adaptive capabilities being its adaptive potential. Interpretations of the studied concept are analyzed, the authors' definition of the enterprise adaptive potential based on the application of a complementary resource-efficient approach is proposed. A methodology for assessing the enterprise adaptive potential is proposed using the main indicators of financial condition: liquidity ratios, financial stability, profitability. An assessment of the adaptive potential of Russian ferrous metallurgy companies under the conditions of the COVID-19 coronavirus pandemic was made.
\end{abstract}

Keywords: enterprise adaptive potential, enterprise sustainability, sustainable development, COVID-19 pandemic, Russian ferrous metallurgy.

\section{INTRODUCTION}

Crisis phenomena in the global economy caused by the pandemic of the new coronavirus infection, geopolitical instability, high volatility of commodity markets and many other factors significantly increase the uncertainty of the business environment, contributing to the fact that the activity of economic entities, even in the short term, becomes a process that is difficult to determine and to predict.

Due to the fact that the enterprises need to adapt to the new challenges, a profound and comprehensive research of the adaptive management issues in the context of the paradigm of sustainable functioning and economic entities development as open socio-economic systems is becoming expedient. Therefore, recently there has been an increase in interest in this issue, both among economists and financial managers at various levels of management [1].

Issues related to the research of economic entities adaptation mechanisms are considered in the works of many national and foreign scientists. Among foreign authors, one can point out the works by R. Ackoff, E. Altman, J. Brigham, L. Gapensky, P. Drucker, J. C. Van Horne, J. Wakhovits, R. Taffler, J. Schumpeter, A. Shapiro, R. Higgins, O. Bowlin, J. Martin, J. von Gigue, Ashby W. Ross, M. Poucock, G. Springate and others.

Russian research scientists of the indicated problems include N. V. Zyablitskaya, I. A. Kuznetsova, L. T. Gilyarovskaya, A. V. Grachev, A. V. Endovitskaya, G. B. Kleiner, L. L. Kalinichenko, I. P. Otenko, O. V. Panfilova, M. V. Romanovsky, E. A. Stoyanova, V. A. Chernenko, A. D. Sheremet and others.

Despite a significant number of relevant scientific works, several theoretical and practical issues related to the research of the enterprise adaptation mechanisms remain controversial and require additional study.

The aim of this work is to develop the theoretical and methodological foundations of the research of the enterprise adaptive potential within the framework of 
the application of the conceptual provisions of the system methodology and the system stability theory.

\section{MATERIALS AND METHODS}

The theoretical and methodological foundations of this study are the provisions of systems theory, theory of system stability, concepts of financial management and financial analysis. In the course of the research, such methods of scientific knowledge were used as a systematic approach, categorical, logical-structural analysis and synthesis, detailing and generalization, grouping and comparison, as well as methods of financial analysis of statistical information.

As part of the study of the adaptive mechanisms of economic entities, the fundamental provisions of the system stability theory should be considered.

Initially, the concept of "stability" was used in natural sciences (mathematics, physics, chemistry, biology), as well as to describe the functioning parameters of technical systems, which are characterized by the ability to return to a state of equilibrium after the system is brought out of this state under the influence of disturbance. Stability is one of the properties of such systems (along with structure, hierarchy, integrity).

With the further development of science, the concept of "sustainability" began to be used in economic research as an integral characteristic of the functioning of socio-economic systems of different levels, carrying out their activities under the influence of permanently changing uncontrolled environmental factors. In relation to such systems, the category "stability" is interpreted as the ability of the system to maintain its integrity and at the same time develop in a given course (to achieve the stated goals), despite the permanent influence of external and internal factors.

The stability of an enterprise as an open socioeconomic system should be considered in terms of two interrelated aspects. The first aspect is the stability of functioning, which characterizes the ability of the system to maintain its internal structure and properties in the course of its activity under the influence of factors of the internal and external environment. The second aspect is the development sustainability, which consists in the ability of the system to maintain its integrity in the long term by improving its internal structure and properties and moving to a qualitatively new level under the influence of factors of the internal and external environment to achieve the stated goals [2]. Thus, the enterprise sustainability (corporate sustainability) is manifested in balanced functioning and development, implying the timeliness and efficiency (economy) of its adaptation to changes in the factors of the internal and external environment while maintaining the basic laws of development, such as purposefulness, dynamism and manageability.

Therefore, we believe that the enterprise adaptation to changing external and internal factors acts as the most important sign of its sustainability. The enterprise adaptation is understood as the process of an adequate response of all its subsystems to the disturbance caused by factors of the internal and external environment. The degree of enterprise adaptive capacity may vary. All other things being equal, the higher the capabilities of an economic entity to adequately respond to changes in the business environment, the more effectively issues are resolved to fulfill the purposes. As a result, the most important objective is to assess the enterprise adaptive abilities (capabilities). The qualitative and quantitative indicator of such an assessment is the enterprise adaptive potential.

The etymology of the term "potential" comes from the Latin "potential", which literally translates as "power", "opportunity". In this context, this concept is widely used in physics, astronomy, biology. Since the 1980s, it has been studied in economics: the term "adaptive potential" along with the concepts of other potentials (economic, financial ones, those of production, labor, innovation) have become conceptual aspects of the study of economic entities properties and characteristics.

Various interpretations of the concept of "enterprise adaptive potential" can be found in the scientific literature. For example, N.V. Zyablitskaya. defines the adaptive potential as "the aggregate capabilities of an enterprise to respond promptly and fully to changes in the external and internal environment by making effective management decisions in order to ensure competitive functioning and sustainable development in the market" [3].

I. P. Otenko notes that "the enterprise adaptive potential characterizes its ability to search for and implement new opportunities associated with dynamic changes of the interaction of the enterprise internal environment with the external environment" [4].

V. A. Grosul, O. D. Rachkovan understand the adaptive potential as "the possibilities of resources, abilities and competences of the enterprise personnel in relation to an adequate response to changes in the external environment in order to ensure the survival, balance or sustainable economic growth of the enterprise" [5].

B. V. Artamonov interprets the adaptive potential as "the ability of the enterprise management to organize the processes of management and planning of production and business processes to create competitive products "at the output" under the conditions of high turbulence of the market environment [6]. 
Summarizing the results of our analysis of the existing definitions of the enterprise adaptive potential, it is necessary to single out two main approaches to the interpretation of this term: one related to the resources and an effective one.

In terms of the resource approach, the enterprise adaptive potential is associated with the economic resources at its disposal: natural, labor, material, financial, informational - or their entire aggregate, or individual types, depending on the interpretations of various authors.

In accordance with the effective approach, the adaptive potential reflects the ability of an enterprise to make rational and efficient use of available resources, which ensures its sustainable functioning in an unstable economic environment.

In our opinion, the use of the resource approach to the definition of the concept of "enterprise adaptive potential" is not entirely correct, because economic resources do not reflect all the constituent elements of the complex category of potential. It is also debatable to associate the capabilities (potential) of an enterprise with the abilities and competencies of management personnel (in making effective management decisions), as noted in the works $[3,5,6]$. In our opinion, the observance of only one of the presented approaches to the definition and disclosure of the economic essence of the enterprise adaptive potential does not provide a complete understanding of it and does not correspond to the modern paradigm of views on this category.

In our opinion, the use of a complementary resource and efficient approach to the definition of the concept of "enterprise adaptive potential" and the detachment of two components in its composition - a resource component, traditionally taken into account by researchers, and an effective component, will allow to combine the scientists' positions regarding the main sources and adaptive capabilities of an enterprise. Within the framework of the indicated complementary approach, we formulate the following definition of the studied category as follows:

The enterprise adaptive potential is its ability to timely and adequately respond to changes in internal and external factors through the effective formation, distribution and use of economic resources in order to ensure sustainable functioning and development in an unstable business environment.

The proposed interpretation conforms with our ideas about the adaptive potential as a sign of enterprise sustainability.

Clarification of the concept and content of the studied category has not only theoretical, but also practical importance, since it allows to formalize the process of assessing the adaptive capabilities of an enterprise to changes in the external and internal environment.

Modern economic literature has no unified approach to the methodology for assessing the adaptive potential of an enterprise. Some authors suggest using traditional indicators characterizing the position of an enterprise in the market (market share, sales volume, competitiveness, profit margin, profitability level, etc.) as the evaluation criteria. Other authors point to the need to assess the adaptive potential of an enterprise based on the use of a certain integral indicator calculated on the basis of a number of private indicators reflecting various aspects of the enterprise adaptation to the new conditions of its financial and economic activities [7].

Since the enterprise functioning and development in a permanently unstable external environment is impossible without appropriate financial support, then, according to the authors, the key indicators for assessing its financial condition should be used as evaluative criteria for the adaptation process of an enterprise: ratios of current, quick, absolute liquidity; financial independence ratio; financial stability ratio; the ratio of the provision of working capital with own sources of financing; return on assets; return on equity.

It is important to note that the enterprise adaptive potential should be assessed for a specific, clearly defined socio-economic situation. A specific socioeconomic situation is determined by a set of conditions and circumstances that are the most significant for the characteristics of the external and internal business environment at a certain point in time. In our opinion, it is advisable to assess the enterprise adaptive capabilities to the new socio-economic situation by calculating the values of the indicators mentioned above for the corresponding period and comparing them with the normative or target values (established at the enterprise). Such an assessment will determine whether the analyzed enterprise was able to continue to function and develop in a given target trajectory under the conditions of a new (changed) socio-economic situation.

The proposed methodological approach can be implemented both in the form of a qualitative and quantitative assessment of the adaptive potential of an enterprise. A point assessment of the fulfillment of the conditions of compliance of the indicators actual values mentioned above with their normative (target) values can be applied for a quantitative measurement can be implemented. 
Table 1. Dynamics of the main indicators of the financial condition of Russian ferrous metallurgy companies for the period $2019-1^{\text {st }}$ half of 2021 .

\begin{tabular}{|c|c|c|c|c|}
\hline \multirow{2}{*}{ Name of the company } & \multicolumn{4}{|c|}{ Indicator value } \\
\hline & As of 31.12.2019 & As of 30.06 .2020 & As of 31.12 .2020 & As of 30.06 .2021 \\
\hline \multicolumn{5}{|c|}{ Current Liquidity Ratio (norm $\geq 2$ ) } \\
\hline PAO "MMK" & 1,66 & 1,93 & 1,42 & 2,02 \\
\hline AO MC "Metalloinvest" & 20,11 & 10,71 & 1,3 & 249,18 \\
\hline PAO "Severstal" & 1,49 & 1,09 & 0,93 & 1,09 \\
\hline PAO "NLMK" & 1,68 & 1,44 & 1,31 & 1,13 \\
\hline PAO "Mechel" & 0,26 & 0,26 & 1,18 & 2,72 \\
\hline PAO "TMK" & 1,05 & 1,52 & 1,64 & 1,17 \\
\hline $\mathrm{AO}$ "ChTPZ" & 0,98 & 1,30 & 1,33 & 1,00 \\
\hline \multicolumn{5}{|c|}{ Quick Liquidity Ratio (norm $\geq 1$ ) } \\
\hline PAO "MMK" & 1,13 & 1,28 & 0,97 & 1,44 \\
\hline AO MC "Metalloinvest" & 20,11 & 10,71 & 1,30 & 249,18 \\
\hline PAO "Severstal" & 1,03 & 0,72 & 0,59 & 0,69 \\
\hline PAO "NLMK" & 1,21 & 1,11 & 0,92 & 0,76 \\
\hline PAO "Mechel" & 0,26 & 0,25 & 1,16 & 2,72 \\
\hline PAO “TMK” & 1,01 & 1,50 & 1,60 & 1,15 \\
\hline $\mathrm{AO}$ "ChTPZ" & 0,81 & 1,07 & 1,01 & 0,69 \\
\hline \multicolumn{5}{|c|}{ Absolute Liquidity Ratio (norm $\geq 0,2)$} \\
\hline PAO "MMK" & 0,71 & 0,61 & 0,60 & 0,62 \\
\hline AO MC "Metalloinvest" & 11,81 & 1,95 & 1,16 & 8,42 \\
\hline PAO "Severstal" & 0,60 & 0,32 & 0,29 & 0,29 \\
\hline PAO "NLMK" & 0,30 & 0,55 & 0,39 & 0,21 \\
\hline PAO "Mechel" & 0,12 & 0,001 & 0,001 & 0,001 \\
\hline PAO "TMK" & 0,22 & 0,33 & 0,42 & 0,24 \\
\hline AO "ChTPZ" & 0,39 & 0,69 & 0,35 & 0,10 \\
\hline \multicolumn{5}{|c|}{ Equity to Total Assets (norm $0,5-0,7$ ) } \\
\hline PAO “MMK" & 0,62 & 0,65 & 0,57 & 0,66 \\
\hline AO MC "Metalloinvest" & 0,57 & 0,51 & 0,25 & 0,86 \\
\hline PAO "Severstal" & 0,36 & 0,34 & 0,40 & 0,44 \\
\hline PAO "NLMK" & 0,56 & 0,52 & 0,45 & 0,42 \\
\hline PAO "Mechel" & 0,03 & 0,03 & 0,03 & 0,03 \\
\hline PAO “TMK” & 0,13 & 0,18 & 0,14 & 0,10 \\
\hline $\mathrm{AO}$ "ChTPZ" & 0,16 & 0,16 & 0,17 & 0,14 \\
\hline \multicolumn{5}{|c|}{ Financial Stability Index $($ norm $\geq 0,8)$} \\
\hline PAO "MMK" & 0,76 & 0,82 & 0,71 & 0,78 \\
\hline AO MC "Metalloinvest" & 0,99 & 0,94 & 0,80 & 0,997 \\
\hline PAO "Severstal" & 0,78 & 0,75 & 0,72 & 0,69 \\
\hline PAO "NLMK" & 0,78 & 0,74 & 0,75 & 0,64 \\
\hline PAO "Mechel" & 0,80 & 0,81 & 0,96 & 0,99 \\
\hline PAO "TMK" & 0,47 & 0,55 & 0,58 & 0,53 \\
\hline $\mathrm{AO}$ "ChTPZ" & 0,55 & 0,63 & 0,78 & 0,68 \\
\hline \multicolumn{5}{|c|}{ Ratio of the Provision of Working Capital with Own Sources of Financing (norm $\geq 0,1)$} \\
\hline PAO "MMK" & 0,04 & 0,02 & $-0,05$ & 0,24 \\
\hline AO MC "Metalloinvest" & $-1,92$ & 0,28 & $-1,88$ & 0,83 \\
\hline PAO "Severstal" & $-0,94$ & $-1,45$ & $-1,33$ & $-0,66$ \\
\hline PAO "NLMK" & $-0,17$ & $-0,28$ & $\begin{array}{ll}-0,61 \\
\end{array}$ & $-0,64$ \\
\hline PAO "Mechel" & $-17,56$ & $-18,90$ & $-20,21$ & $-24,06$ \\
\hline PAO “TMK" & $-0,57$ & $-0,18$ & $-0,25$ & $-0,64$ \\
\hline $\mathrm{AO}$ "ChTPZ" & $-0,90$ & $-0,75$ & $-1,79$ & $-1,67$ \\
\hline \multicolumn{5}{|c|}{ Return on Assets (calculated on the basis of net profit), \% } \\
\hline PAO "MMK" & 14,27 & 5,25 & 12,57 & 23,28 \\
\hline AO MC "Metalloinvest" & 47,32 & 56,08 & 120,75 & 160,67 \\
\hline PAO "Severstal" & 23,82 & 6,41 & 22,63 & 22,65 \\
\hline PAO "NLMK" & 14,95 & 5,83 & 11,05 & 18,49 \\
\hline PAO "Mechel" & 0,7 & $-0,15$ & $-0,52$ & 0,42 \\
\hline PAO "TMK" & 5,79 & 7,02 & 5,95 & 1,17 \\
\hline $\mathrm{AO}$ "ChTPZ" & 1,16 & 1,71 & 3,66 & $-2,20$ \\
\hline \multicolumn{5}{|c|}{ Return on equity (calculated on the basis of net profit), \% } \\
\hline PAO "MMК” & 22,63 & 8,23 & 21,06 & 37,66 \\
\hline AO MC "Metalloinvest" & 96,26 & 105,29 & 261,75 & 216,31 \\
\hline PAO "Severstal" & 59,17 & 18,19 & 59,36 & 53,81 \\
\hline PAO "NLMK" & 26,25 & 10,87 & 22,02 & 42,48 \\
\hline PAO "Mechel" & 20,16 & $-4,62$ & $-17,46$ & 15,29 \\
\hline PAO "TMK" & 48,57 & 43,67 & 42,98 & 9,78 \\
\hline $\mathrm{AO}$ "ChTPZ" & 6,0 & 11,03 & 22,77 & $-14,33$ \\
\hline
\end{tabular}


It should be emphasized that in practice, each adaptation change is associated with financial and time losses, which are not always compensated by a positive effect. That is why the adaptive potential of an enterprise should be assessed in a comprehensive manner, taking into account such criteria as the adaptation speed; adaptation cost (cumulative adaptation costs); adaptation effectiveness (its impact on the structure and cost of enterprise capital) [8]. In our opinion, the proposed methodological approach makes it possible to take into account these conceptual aspects (criteria) of adaptation.

\section{RESULTS AND DISCUSSION}

Approbation of the proposed methodological approach consists in assessing the adaptive potential of Russian ferrous metallurgy companies under the conditions of the COVID-19 coronavirus infection pandemic. The choice of research objects is not random. Ferrous metallurgy is a basic branch of the Russian economy, an instrument for ensuring national security, a source of employment and income for a significant part of the population.

The sector of the Russian ferrous metallurgy includes about one and a half thousand enterprises, however, the industry is highly concentrated [9]. This is evidenced by the fact that only 9 companies are involved in more than $80 \%$ of the total production of ferrous metallurgy products in Russia: AO MC Metalloinvest (Limited Company, Managing Company), PAO Magnitogorsk Metallurgical Plant (Public JointStock Company) (PAO MMK), PAO Novolipetsk Metallurgical Plant (Public Joint-Stock Company) (PAO NLMK), PAO Severstal (Public Joint-Stock Company), PAO Mechel (Public Joint-Stock Company), AO EvrazHolding (Limited Company), as well as pipe companies PAO Pipe Metallurgical Company (Public Joint-Stock Company) (PAO TMK), AO United Metallurgical Company (Limited Company), AO Chelyabinsk Tube Rolling Group plant (Limited Company) (AO “ChTPZ"). The listed companies, being export-oriented, are among the key players in the respective world commodity markets. In this regard, their adaptive capabilities and stability of functioning in the new conditions of the pandemic play a significant role in ensuring the diversification of the Russian economy and strengthening its competitive position in the global market [10].

The analyzed sample includes 7 out of 9 above listed companies. The exclusion of AO EvrazHolding and AO United Metallurgical Company from the sample is due to the fact that they do not publish their interim financial statements in the public domain.

As part of assessing the adaptive potential of the companies under study under the conditions of the
COVID-19 pandemic, which began in 2020, it is necessary to calculate the values of the analyzed indicators as of $31.12 .2019 ; 30.06 .2020 ; 31.12 .2020$; 30.06.2021.

The results of the analysis conducted are demonstrated in Table 1. Summarizing the results of the analysis, it should be mentioned that the impact of the COVID-19 pandemic on Russian metallurgical companies is especially noticeable in the first half of 2020 and is expressed mainly in a decrease in profitability indicators.

As for the financial ratios characterizing the liquidity, solvency and financial stability of the companies under study, no unambiguous negative dynamics was revealed under the influence of the pandemic. At the same time, however, for most of the metallurgical holdings, the actual values of financial ratios do not conform with the standards throughout the analyzed period (including the pre-crisis period), this is especially evident in relation to the ratios of current liquidity, financial independence and financial stability.

Among the companies studied, PAO "MMK", AO MC "Metalloinvest" are characterized by a high level of adaptive capacity under the pandemic conditions. With regard to the remaining five metallurgical holdings, the adaptive potential is assessed as insufficient (low), which is demonstrated in the discrepancy between the actual values of the analyzed indicators and the standards, as well as in the negative nature of their dynamics.

\section{CONCLUSIONS}

The results of the authors' research, devoted to the study of the adaptive potential of an enterprise from the standpoint of a systematic approach, make it possible to reveal more profoundly its economic essence, clarify the substantive nature of its definition and supplement the corresponding methodological apparatus of its assessment. The approbation of the proposed methodological approach demonstrated the extreme vulnerability of Russian ferrous metallurgy enterprises to the challenges of the COVID-19 pandemic, due to the fact that the level of adaptive capacity is assessed as insufficient in $70 \%$ of the analyzed sample.

\section{REFERENCES}

[1] O. I. Gonchar, Motivational Aspects of Adaptive Management Potential of Enterprise, SCIENTIFIC BULLETIN OF POLISSIA, 2 (2016) pp. 79-84.

[2] Yu. A. Dolgikh, Formation and functioning of the financial stability management system of an enterprise: thesis. ... Candidate of Economic Sciences. Yekaterinburg, 2019, pp. 204. 
[3] N. V. Zyablitskaya, Methodology of a comprehensive assessment of the adaptive potential of oil and gas enterprises: author's abstract of thesis ... Doctor of Economic sciences. St. Petersburg, 2012, pp. 37.

[4] I. P. Otenko, Strategic management of enterprise potential: monograph, KNUE, 2006, pp. 256.

[5] V. A. Grosul, Methodological foundations for assessing the adaptive potential of a trading enterprise, Scientific Bulletin of the Odessa National Economic University, 6(226) (2015) pp. 74-89.

[6] B. V. Artamonov, Strategic potential of the enterprise and its main components, Scientific Bulletin of MSTU CA, 202 (2014) pp. 5-9.

[7] V. A. Grosul, O. A. Kruglova, O. D. Rachkovan, Adaptive potential complex assessment in the system of the trade enterprises adaptive management, MARKETING AND MANAGEMENT OF INNOVATIONS, 1 (2017) pp. 213-222.

[8] A. Nakonechna, A. Laktionova, Financial Architecture Adaptation of Enterprises: Quantitative Dominants in the Cyclical Economic Development, Economic archive, 3 (2017) pp. 318.

[9] On the approval of the Ferrous Metallurgy Development Strategy in Russia for 2014-2020 and until 2030 and of the Non-Ferrous Metallurgy Development Strategy in Russia for 2014-2020 and until 2030: order of the Ministry of Industry and Trade of Russia dated 05.05.2014 №. 839, http://base.consultant.ru.

[10] Yu. A. Dolgikh, E. A. Smorodina, Yu. E. Slepukhina, Impact of Covid-19 Coronavirus Infection Pandemic on Financial Stability of Russian Black Metals Companies, Proceedings of the Research Technologies of Pandemic Coronavirus Impact (RTCOV 2020). Advances in Social Science, Education and Humanities Research, 486 (2020) pp. 264-271. 